\title{
The Complexity of Weight Loss Counseling
}

\author{
Jessica L. J. Greenwood, MD, MSPH
}

Counseling is a complex and dynamic interaction between provider and patient. Many questions surface with regard to the management of overweight and obese patients. The article, "What Do Physicians Recommend to their Overweight and Obese Patients?" in this issue of The Fournal of the American Board of Family Medicine augments evidencebased knowledge on this matter. ${ }^{1}$ Previous research has answered some questions, yet others remain.

Clinicians should provide weight management counseling for all patients, adults and children., ${ }^{2,3}$ However, effective communication is reciprocal. The article in this issue reports $75.5 \%$ of physicians report addressing weight loss with their patients. ${ }^{1}$ One must consider whether patients receive the message. According to the 1996 Behavior Risk Factor Surveillance System (BRFSS), only 30\% and $42 \%$ of those who are overweight or obese, respectively, reported that their clinician advised them to lose weight within the past year. ${ }^{4}$ Similarly, other studies indicate that only $24 \%$ of overweight and $42 \%$ to $49 \%$ of obese patients report discussion regarding weight loss with their doctor $(P<$ $.001){ }^{5,6}$ Furthermore, clinician documentation indicates that few children receive weight loss management. $^{7}$

Studies suggest discord between clinician and patient perceptions, as well. Many factors influence a provider's decision to counsel on weight loss. One

This article was externally peer reviewed.

Submitted 15 December 2008; revised 23 December 2008; accepted 5 January 2009.

From Division of Public Health Department of Family and Preventive Medicine, University of Utah School of Medicine, Salt Lake City, Utah.

Funding: none.

Conflict of interest: none declared.

Corresponding author: Jessica L. J. Greenwood, MD, MSPH, Division of Public Health, Department of Family and Preventive Medicine, University of Utah School of Medicine, 375 Chipeta Way, Suite A, Salt Lake City, Utah 84108 (E-mail: jessica.greenwood@hsc.utah.edu).

See Related Article on Page 115. common factor is the clinician's perception of the patient's receptivity to suggestions. ${ }^{8}$ A patient's motivation is often cited by physicians as a great barrier to change. ${ }^{9}$ A provider's perception of motivation, however, is not necessarily equivalent to the patient's reported motivation level. ${ }^{10}$ This differential can negatively affect communication.

The definition of successful weight loss can also be a source of discord between a clinician and a patient. In the Phelan et al article published in this issue, only $10.3 \%$ of the providers indicated that a $5 \%$ to $10 \%$ weight loss in a 220 pound, 5 foot 6 inch (body mass index $[\mathrm{BMI}]=35.6$ ) patient would be "acceptable," whereas $30 \%$ reported that this would be "disappointing." ${ }^{1}$ Unfortunately, there is no reference to time with this statistic, which would help with evaluating such weight loss. If such a patient lost 2 pounds per week for 2 months, they would have lost $8 \%$ of their body weight (BMI = 33.0), which is a very healthy weight loss pattern. Conversely, if such a patient did not lose any more weight and sustained this weight loss over the course of several or many months, this weight loss would not be ideal. ${ }^{11}$ It is not necessarily bad, though. As mentioned in the Phelan et al article, sustained, moderate ( $5 \%$ to $10 \%$ ) weight loss can be beneficial. ${ }^{11-13}$ Others report a more subjective provider definition of success, focusing on improved habits rather than standardized weight loss goals. Fifty-three percent of clinicians in one survey did not define success for obesity counseling by weight loss, and only $1 \%$ defined success by standard weight loss goals, ie, BMI $<30$. $^{8}$

A provider's advice is very influential. In one study, obese individuals whose provider advised weight loss had 3 times the odds of attempting weight loss compared with those not advised to lose weight. $^{6}$ The majority of overweight $(>70 \%)$ and obese $(>88 \%)$ seeking care from primary care physicians want their doctor to help with them with their weight; $63 \%$ and $84 \%$, respectively, believe their doctor can help $(P<.001) .{ }^{5}$ Overall, patients are comfortable with discussing weight and feel 
weight loss is important. ${ }^{5}$ Thus, providers should consistently engage with them in such matters.

The article highlights many evidence-based behaviors associated with excess weight. ${ }^{1}$ Clinicians should focus some behaviors toward the child patient versus adult patient. Recommendations for decreasing screen time (ie, television, video games, computer, etc) should focus on the child patient. ${ }^{3,14}$ Furthermore, recommendations for the amount of time engaged in physical activity differs for the adult and child. Adults (18 to 65 years) should obtain a minimum of 30 minutes of moderateintensity aerobic exercise on 5 days each week, whereas children and adolescents should obtain at least 60 minutes of the same on every day of the week. ${ }^{15,16}$

Weight management is a very complex issue and can seem a daunting task. Clinicians are very influential and have opportunity to encourage behavior change. Scientific evidence continues to expand to guide counseling efforts; however, barriers remain. Although clinicians report addressing weight loss, it is important that the patient understands and receives these messages. Further, there is evidence to support specific associations between dietary patterns, physical activity, and weight. These associations need to be tailored to appropriate patient populations. Continued efforts are necessary to determine the most effective and efficient means for weight loss counseling.

The article "What Do Physicians Recommend to Their Overweight and Obese Patients?" concludes with the issue of time constraints for primary care providers. ${ }^{1}$ Time limitation is not the monstrous barrier as frequently assumed. ${ }^{8}$ Though at times referral to specialty care is warranted, primary care providers often have the benefit of frequent follow up and the option of billing for time. Counseling is a dynamic interaction that requires clinicians to balance time and benefit. The rewards, however, are substantial and life changing.

\section{References}

1. Phelan S, Nallari M, Darroch F, Wing R. What do physicians recommend to their overwieght and obese patients? J Am Board Fam Med 2009;22:115-22.

2. Nawaz H, Katz DL. American College of Preventive Medicine Practice Policy statement. Weight management counseling of overweight adults. Am J Prev Med 2001;21:73-8.
3. Rao G. Childhood obesity: highlights of AMA Expert Committee recommendations. Am Fam Physician 2008;78:56-63.

4. Sciamanna CN, Tate DF, Lang W, Wing RR. Who reports receiving advice to lose weight? Results from a multistate survey. Arch Intern Med 2000;160:2334-9.

5. Potter MB, Vu JD, Croughan-Minihane M. Weight management: what patients want from their primary care physicians. J Fam Pract 2001;50:513-8.

6. Galuska DA, Will JC, Serdula MK, Ford ES. Are health care professionals advising obese patients to lose weight? JAMA 1999;282:1576-8.

7. Dorsey KB, Wells C, Krumholz HM, Concato J. Diagnosis, evaluation, and treatment of childhood obesity in pediatric practice. Arch Pediatr Adolesc Med 2005;159:632-8.

8. Sussman AL, Williams RL, Leverence R, Gloyd PW, Jr., Crabtree BF. The art and complexity of primary care clinicians' preventive counseling decisions: obesity as a case study. Ann Fam Med 2006; 4:327-33.

9. Jallinoja P, Absetz P, Kuronen R, et al. The dilemma of patient responsibility for lifestyle change: perceptions among primary care physicians and nurses. Scand J Prim Health Care 2007;25:244-9.

10. Befort CA, Greiner KA, Hall S, et al. Weight-related perceptions among patients and physicians: how well do physicians judge patients' motivation to lose weight? J Gen Intern Med 2006;21:1086-90.

11. National Heart, Lung, and Blood Institute. Clinical guidelines on the identification, evaluation, and treatment of overweight and obesity in adults: The evidence report. Bethesda (MD): National Institutes of Health; 1998. p. 262.

12. Knowler WC, Barrett-Connor E, Fowler SE, et al. Reduction in the incidence of type 2 diabetes with lifestyle intervention or metformin. N Engl J Med 2002;346:393-403.

13. Lindstrom J, Louheranta A, Mannelin M, et al. The Finnish Diabetes Prevention Study (DPS): Lifestyle intervention and 3-year results on diet and physical activity. Diabetes Care 2003;26:3230-6.

14. Plourde G. Preventing and managing pediatric obesity. Recommendations for family physicians. Can Fam Physician 2006;52:322-8.

15. Centers for Disease Control. Physical Activity for Everyone: How much physical activity do children need? Available at http://www.cdc.gov/physicalactivity/ everyone/guidelines/children.html. Accessed 3 November 2008.

16. Haskell WL, Lee IM, Pate RR, et al. Physical activity and public health: updated recommendation for adults from the American College of Sports Medicine and the American Heart Association. Med Sci Sports Exerc 2007;39:1423-34. 